\title{
DIREITO AO AMBIENTE E O DIREITO À MORADIA: COLISÃO E PONDERAÇÃO DE DIREITOS FUNDAMENTAIS.
}

\author{
ENVIRONMENTAL LAW AND THE RIGHT TO HOUSING: COLLISION AND \\ WEIGHTING OF FUNDAMENTAL RIGHTS.
}

João Emilio de Assis Reis

\section{RESUMO}

O presente trabalho é um ensaio teórico que trata de analisar o conflito entre o direito fundamental à moradia e o direito fundamental ao meio ambiente. Partindo da análise da evolução da incorporação da tutela da moradia e do ambiente ao ordenamento jurídico como direitos, analisa a presença de ambas como direitos fundamentais na Constituição de 1988. Partindo do pressuposto de inexistência de hierarquia entre ambos os direitos, busca finalmente apresentar o método da ponderação de valores e da concordância prática, como forma de solução de conflito entre direitos fundamentais.

Palavras-chave: Direito ao Ambiente; Direito à Moradia; Conflito de Direitos Fundamentais; Urbanização;

\begin{abstract}
This paper is a theoretical rehearsal that analyzes the conflict between the fundamental right to housing and the fundamental right to the environment. Based on the analysis of the evolution of the incorporation of housing and protection of the environment in the law, analyzes the presence of both as fundamental rights in the 1988 Constitution. Assuming absence of hierarchy between both rights, search finally present the method and the weighting of practical agreement as a way of resolving conflict between fundamental rights.
\end{abstract}

Key-words:Conflict of Fundamental Rights; Right to Environment; Right to Housing; Urbanization;

*Professor de Direito Civil do UNASP-SP. Advogado atuante em Minas Gerais. Mestre em Direito Privado pelo UNIFLU-RJ e Doutorando em Direito Urbanístico pela PUC-SP. E-mail: jotaemilio@gmail.com 


\section{CONSIDERAÇÕES INICIAS}

O intenso crescimento urbano ocorrido no mundo a partir do século $X X$ tem provocado inúmeras mudanças socioeconômicas e territoriais. A expansão das cidades, em especial em países em desenvolvimento é ainda pior, dada a circunstância de aliar urbanização intensiva, degradação ambiental, com desigualdades socioeconômicas.

O contextodos países em desenvolvimento é especialmente problemático, uma vez que o poder público nesses Estadosao mesmo tempo é omisso na proteção de bens ambientais naturais e deixa de implementar políticas públicas adequadas à efetivação de direitos sociais, especialmente no que tange ao direito à moradia. $O$ processo de urbanização pelo qual passou Brasil a partir da industrialização tardia cria um quadro caótico, em razão da explosão demográfica das cidades, com a taxa de urbanização saltando de $31,2 \%$ em 1940 para $81,2 \%$ no ano 2000 (BRITO, 2001). O que por si só representa fenômeno de grandes proporções, sem o devido acompanhamento de implementação de acesso a serviços básicos e sem o acompanhamento de políticas públicas que garantam as funções sociais básicas da cidade, torna-se um problema maior.

Além disso, piora o referido quadro o histórico regime de ocupação da terra, quedesde os tempos coloniais se concentrou nas mãos de poucos. "Uma história deocupação que gerou e consolidou uma estrutura de propriedade das mais concentradas do mundo e, o pior, uma imensidão de terras sem uso algum. Como consequência, uma legião de agricultores sem trabalho e sem terras." (GERMANI, 2006, 142). A questão de se tratar do campo ou da cidade nunca fez muita diferença do ponto de vista da democracia na ocupação do solo.

Tal quadro ocorrido especialmente a partir de meados do século $X X$, proporcionouum déficit habitacional de grandes proporções, especialmente porque a urbanização não foi acompanhada de um processo de planejamento racional e inclusivo das cidades, proporcionando a situação de ocupação desordenada do território. 


\begin{abstract}
A invasão de terra urbana tem sido parte do processo de urbanização. Ela é estrutural e institucionalizada em razão do mercado imobiliário excludente e da ausência de política sociais. Invasão, termo muitas vezes rejeitado, é a ocupação de terra alheia, muitas vezes por falta de alternativas. Os loteamentos ilegais, por outro lado, não são terras invadidas, mas apresentam ilegalidades, quanto à titulação ou exigências urbanísticas. (BERÉ, 2005, 104)
\end{abstract}

Assim tem-se início de processos de ocupação, que muito frequentemente se darão em áreas em que se compromete o meio ambiente, como ocorre frequentemente na ocupação de áreas verdes e áreas de proteção a mananciais. Essas ocupações, ao longo da história da urbanização sempre foram ignoradas pelo poder público e pela cidade oficial, até por estarem inseridas fora do mercado imobiliário formal, que sempre teve com ela uma relação de conivência, promovendo anistias periódicas permitindo a regularização e o fornecimento em certa medida de infraestrutura urbana (MARICATO apud BERÉ, 2005, 104).

O crescimentodesordenado das cidades brasileiras compele boa parte da população urbana para áreas marginais onde se constituem assentamentos marginais, boa parte deles em áreas de especial tutela ambiental, como áreas verdes e áreas de mananciais.A situação criada pela omissão do Estado cria verdadeiros problema do ponto vista social e jurídico, posto que famílias as quais nunca se propiciou o direito fundamental à moradia, acabam por ocupar áreas protegidas com fundamento no direito coletivo ao ambiente equilibrado e de acesso aos recursos naturais.

A partir desse cenário problemático, do ponto de vista social e jurídico, o presente texto busca de analisar a resposta jurídica ao problema do conflito fático que ocorre entre o direito ao meio ambiente e a necessidade de preservação ambiental de um lado, e de outro lado o direito fundamental à moradia, num contexto de déficit habitacional histórico e ausência de políticas públicas de acesso à moradia.

Partindo da análise construção histórica do direito à moradia até a sua inserção no texto constitucional brasileiro e suas consequências jurídicas, repetindose o mesmo processo com relação ao direito ao ambiente, analisa-se ao final a questão do conflito entre os direitos, a partir da metodologia proposta pelo direito constitucional contemporâneo para os casos colisão de interesses REVISTA DO DIREITO UNISC, SANTA CRUZ DO SUL № 41| p. 65 - 88| NOV - DEZ 2013 
constitucionalmente protegidos e direitos fundamentais, onde se busca a ponderação e a partir dela a harmonização dos direitos envolvidos, recorrendo finalmente a um julgado, como forma de verificar na prática, se é possível a referida harmonização.

\section{O DIREITO À MORADIA E SUA CONSTRUÇÃO TEÓRICA}

A questão da moradia é objeto de estudo nas mais variadas ciências, dada a compreensão de sua essencialidade na vida do homem. Essa essencialidade se dá por diversos motivos, desde os mais simples que se pode imaginar, como a necessidade do homem primitivo de um refúgio para se proteger dos animais ferozes e de se abrigar das condições do tempo, até mesmo pela compreensão dohomem como um ser cultural, que transforma e recria o mundo à sua volta para sobreviver.

A questão da moradia como a necessidade de ter um espaço próprio, um "lugar pra ficar", é própria da essência humana: seja pela necessidade de um ponto de referência que permita a localização e individualização de certa ou certas pessoas, por questões de saúde, ou mesmo pela condição de realizadora de outros direitos, como o Direito ao Sossego, à proteção da intimidade, à segurança e mesmo à liberdade, visto que a liberdade pressupõe um mínimo de espaço para a individualidade.

Desde a antiguidade, a ideia de lar transcende a questão da utilidade imediata, consistindo num espaço reservado a uma determinada família, sagrado e inviolável. Lar era o espaço territorial onde uma determinada família se estabelecia permanentemente e ali estabeleceria sua religião doméstica.

E a família, destarte, ficando, por dever e por religião, agrupada ao redor do seu altar, fixa-se ao solo como o próprio altar. A ideia de domicilio surge naturalmente. A família está vinculada ao altar e este, por sua vez, encontra-se fortemente ligado ao solo; estreita relação se estabeleceu portanto entre o solo e a família. Aí deve ser sua residência permanente, que jamais abandonará, a não ser quando alguma força superior a isso a constranja. Como o lar, a família ocupará sempre esse lugar. O lugar pertence-lhe: é sua propriedade, propriedade não de um único homem, mas 
de uma família, cujos diferentes membros devem vir, um após outro, nascer e morrer ali. (COULANGES, 1978, 50)

Embora se possa encontrar como exceções a Constituição do México (1917) e a Constituição da República de Weimar (1919), nas origens do constitucionalismo social, o direito à moradia passa por um movimento de reconhecimento histórico paulatino, primeiramente no plano internacional. É primeiramente reconhecido e reafirmado como um direito humano básico por diversos tratados internacionais, para só então, gradativamenteser reconhecido e incorporado aos diversos ordenamentos jurídicos dos Estados soberanos. A partir daí tem-se os direitos sociais previstos naquelas Constituições pioneiras revisitado.

"Os organismos internacionais elaboraram o conceito para o que se pode identificar como direito à moradia, com base na defesa de um adequado padrão de vida humano que toda pessoa tem direito para si e para seus familiares". (MELO, 2010, 37)

O primeiro documento de grande repercussão internacional a referir-se a moradia, foias cartas de Atenas, elaboradas no contexto do Congresso Internacional de Arquitetura e Urbanismo em 1933. Muito embora não seja um documento de repercussão jurídica, refere-se às funções sociais que uma cidade deve proporcionar, entre elas "habitar". Mesmo sem repercussão jurídica por si só, as Cartas de Atenas acabam por criar a noção de cidade como função social, passando-se a compreensão do espaço urbano mais que simplesmente um aglomerado de pessoas e edificações, que inclusive é incorporado ao texto constitucional brasileiro no art. 182. A noção de função social da cidade preconizada nas Cartas de Atenas termina por firmar-se como o marco teórico inicial para a discussão do direito à moradia e sua incorporação aos ordenamentos jurídicos nacionais, pois é pioneira na compreensão da moradia como premissa para o desenvolvimento do ser humano em suas potencialidades.

A primeira previsão jurídica específica sobre moradia que para nós tem importância remonta à Declaração Universal dos Direitos Humanos, que estabelece em seu art. XXV "Toda pessoa tem direito a um padrão de vida capaz de assegurar a si e a sua família, saúde e bem-estar, inclusive alimentação, vestuário, habitação, cuidados médicos e serviços sociais indispensáveis". 
Ao lado do referido dispositivo, o inciso XII da referida Declaração Universal prevê a tutela do lar do indivíduo, - que se pode considerar uma referência indireta à moradia - dispondo que "Ninguém será sujeito a interferências em sua vida privada, na sua família, no seu lar ou na sua correspondência, nem a ataques à sua honra ou reputação. Toda pessoa tem direito à proteção da lei contra tais interferências ou ataques".

Em 1966 foi aprovado, também no âmbito das Nações Unidas, o Pacto Internacional dos Direitos Econômicos, Sociais e Culturais, que só entra em vigência em 1976, em cujo art. 11 estabelece que "Os Estados Partes no presente pacto reconhecem o direito a toda pessoa a um nível de vida adequado para si próprio e sua família, inclusive alimentação, vestimenta e moradia adequada, assim como uma melhoria contínua de suas condições de vida".

Em 1976, tem-se a realização de importante conferência internacional para debate do tema em Vancouver, no Canadá, denominada Conferência das Nações Unidas sobre Assentamentos Humanos - HABITAT I. Nesta conferência discutiu-se a necessidade de adequada habitação para todos e o desenvolvimento de assentamentos humanos sustentáveis em um mundo em urbanização estabeleceram-se metas a serem atingidas pelos signatários. O documento originado daquela conferência, a Declaração de Vancouver sobre Assentamentos Humanos, estabelece em sua III Seção, item 8que

Habitação e serviços adequados são um direito humano básico que obriga
os governos a assegurar a sua realização por todas as pessoas,
começando com assistência direta ao menos favorecidos através de
programas de ajuda mútua e de ação comunitária. Os governos devem se
esforçar para remover todos os obstáculos que impedem realizações
desses objetivos. ${ }^{1}$

Do ponto de vista do Direito Constitucional, a primeira carta política a tratar a moradia como um direito constitucional é a Constituição Política dos Estados Unidos Mexicanos de 1917, que no Título I, Capítulo I, que trata dos Direitos Humanos e suas garantias, menciona o Direito à moradia no art. $4^{\circ}$ ao dispor que toda família tem direito a desfrutar de uma moradia digna e adequada e que a lei estabelecerá os

\footnotetext{
${ }^{1}$ Texto literal: Adequate shelter and services are a basic human right which places an obligation on Governments to ensure their attainment by all people, beginning with direct assistance to the least advantaged through guided programmes of self-help and community action. Governments should endeavour to remove all impediments hindering attainments of these goals.
}

REVISTA DO DIREITO UNISC, SANTA CRUZ DO SUL NN 41| p. 65 - 88|NOV - DEZ 2013 
instrumentos e apoios necessários a fim de alcançar tal objetivo ${ }^{2}$. Assim, a Moradia tem cunho constitucional, tratando-se por disposição expressa de norma programática, já que sua eficácia dependia de norma constitucional regulamentadora que viesse efetivar o Direito. Cabe observar contudo, que a mesma constituição estabelece como "base" da Seguridade Social, a disponibilização aos trabalhadores habitações baratas para aquisição ou locação e determina a criação de um fundo nacional de habitação que proporcione acesso a crédito barato e suficiente para aquisição de moradias adequadas. ${ }^{3}$

Da mesma forma a Constituição da República de Weimar (1919) também reconhece a importância da moradiaem seu artigo 155 dispõe que o fracionamento e o uso do solo serão controlados pelo Estado de forma a impedir abusos e a permitir a todo alemão uma morada saudável e a todas as famílias alemãs, em especial as mais numerosas, uma morada e um patrimônio que atenda suasnecessidades.

O direito à moradia foi reconhecido de forma expressa como direito fundamental constitucionaltardiamente no contexto da Emenda Constitucional No. 26 de 2000, que o incluiu no Titulo II, que trata dos direitos fundamentais e no Capítulo II, que trata dos Direitos Sociais.

São direitos sociais a educação, a saúde, o trabalho, a moradia, o lazer, a segurança, a previdência social, a proteção à maternidade e a infância, a assistência aos desamparados, na forma desta Constituição. (art. 6, Constituição Federal).

\begin{abstract}
Direitos Sociais, prestações positivas proporcionadas pelo Estado direta ou indiretamente, enunciadas em normas constitucionais, que possibilitam melhores condições de vida aos mais fracos, direitos que tendem a realizar a igualização de situações sociais desiguais. São, portanto, direitos que se ligam ao direito de igualdade. Valem como pressupostos do gozo de direitos individuais na medida em que criam condições materiais mais propícias ao auferimento da igualdade real, o que, por sua vez, proporciona condição mais compatível com o exercício de sua atividade. (SILVA, 2005, 286).
\end{abstract}

\footnotetext{
2 Texto literal: "Toda familia tiene derecho a disfrutar de vivienda digna y decorosa. La Ley establecerá los instrumentos y apoyos necesarios a fin de alcanzar tal objetivo"

${ }^{3}$ Se proporcionarán a los trabajadores habitaciones baratas, en arrendamiento o venta, conforme a los programas previamente aprobados. Además, el Estado mediante las aportaciones que haga, establecerá un fondo nacional de la vivienda a fin de constituir depósitos en favor de dichos trabajadores y establecer un sistema de financiamiento que permita otorgar a éstos crédito barato y suficiente para que adquieran en propiedad habitaciones cómodas e higiénicas, o bien para construirlas, repararlas, mejorarlas o pagar pasivos adquiridos por estos conceptos.
} 
Os direitos Sociais surgem no contexto do constitucionalismo social. Aquele modelo de Estado surgido das revoluções liberais do século XVIII preocupava-se basicamente com as liberdades públicas, com o arbítrio do soberano e por isso, tinha como preocupação básica garantir a liberdade individual, mantendo a atuação do poder público equidistante da esfera privada e garantir a igualdade formal, no sentido de que o poder público trata todos como iguais. No entanto, essas conquistas pouco fizeram pela grande massa de despossuídos, de forma que pouco mais de um século depois de surgido, o modelo de Estado Liberal entrava em crise.

Os Estados europeus se encontravam em profundas desigualdades sociais nos séculos XVIII e XIX, desigualdades que só se acirraram na Revolução Industrial, ao criar mais miséria de um lado, com pessoas que trabalhavam em condições subhumanas, e de outro, mais concentração de riqueza. As constantes crises e instabilidade social que se seguiram terminam por permitir 0 início do reconhecimento de direitos sociais ao fim de um longo processo histórico. Estes nascem de concessões, diante do temor provocado pelas revoluções comunista e mexicana, pelos movimentos anarquistas e pelo sindicalismo nascente que criavamriscos derrubada dos regimes liberais então vigentes.

Desta forma aparecem os Direitos Sociais,ante a compreensão de que o Estado deve atuar no sentido de garantir condições mínimas de vida para os seus cidadãos, e que a mera garantia das liberdades públicas está aquém da função estatal. Os direitos sociais são, sob essa perspectiva, fins da ação do Estado, e não limites desta ação, como o caso das liberdade públicas.

\footnotetext{
Obedecem, primordialmente, ao princípio da solidariedade (ou fraternidade, no tríptico da Revolução Francesa), a qual se impõe, segundo os ditames da justiça distributiva ou proporcional, a repartição das vantagens ou encargos sociais em função das carências de cada grupo ou estrato da sociedade (COMPARATO, 2004, 335).
}

Muito embora todo esse processo histórico-conjuntural de consolidação dos direitos sociaisé preciso cuidado para não que se vincule esses direitos a demandas sociais e econômicas de determinado contexto, atribuindo-lhes eventual função reparadora de desigualdades históricas ou função assistencial. Os direitos fundamentais sociais devem ser compreendidos na sua essência de direitos fundamentais, como um conjunto de direitos essenciais e inafastáveis constitutivos 
da personalidadee da dignidade humana, tanto quanto os direitos civis e políticos, e tão inarredáveis quanto estes.

Do reconhecimento da fundamentalidade desses direitos decorre especial status de proteção, tanto em sentido material como em sentido formal. Da fundamentalidade formal resulta da compreensão dos Direitos fundamentais como ápices de nosso ordenamento jurídico e nesse sentido cuida-se de direitos de natureza supralegal. Além disso, encontram-se submetidos aos limites materiais e formais de reforma da constituição e, por derradeiro, cabe salientar que são de aplicação imediata (Constituição Federal art. 5․ $§ 1^{\circ}$.). Da fundamentalidade material, decorre serem os direitos fundamentais elemento constitutivo da Constituição material, contendo decisões fundamentais sobre a estrutura básica do Estado e da Sociedade. (SARLET, 2011, 75).

Essas decisões, ou opções políticas do Estado, no caso da proteção que a Constituição brasileira concede aos direitos sociais são inequívocas, principalmente se observado o contexto constitucional, do qual consta verdadeira sensibilidade social, já que é objetivo constitucional a construção de uma sociedade mais justa e menos desigual, ao invés da ideia tradicional e ineficaz de simplesmente se garantir as liberdades. Essa leitura do texto constitucional é consistente, posto que conforma valores como os que emanam do princípio da dignidade da pessoa humana, fundamento da República, e ainda com outros valores constitucionais e objetivos a se alcançar conforme estabelecido na Constituição, como "construir uma sociedade livre, justa e solidária" (art. 3, I); "erradicar a pobreza e a marginalização e reduzir as desigualdades sociais e regionais" (art. 3, III); "promover o bem de todos, sem preconceitos de origem, sem preconceitos de origem, raça, sexo, cor, idade, e quaisquer formas de discriminação" (art. 3, IV).

Daí percebe-se a importância da construção teórica que precede a positivação de Direitos Sociais e do caso específico do Direito à Moradia. Toda a Construção teórica e a evolução paulatina do reconhecimento dos DireitosSociais e do Direito à moradia no plano internacional, permitem a própria conformação do direito, a explicitação de sua essencialidade, e proporciona a sua fundamentação quando da sua efetivação, o que, aliás é pressuposto da efetivação de qualquer direito na tradição ocidental. 
A positivação dos direitos sociais, por outro lado, é o que garante a sua eficácia social. O reconhecimento de Direito como essencial depende do seu reconhecimento jurídico como tal. Num estado com princípios democráticosa proteção jurídica de algo que se entenda por direito resulta de um processo de legitimação indispensável. Esse processo de legitimação em nível constitucional é que torna o direito exigível explicitando sua origem como escolha da vontade coletiva, nos temos da Constituição, cabendo ao Estado Democrático concretizador dessa vontade, instrumentalizá-lo.

Embora exijam prestações positivas do Estado, através da execução de políticas públicas, os Direitos Fundamentais Sociais são concebidos tradicionalmente como normas de eficácia limitada, cuja aplicabilidade é mediata e de eficácia reduzida. No entanto a emergência cada vez maior um significativo número de normas de caráter programático, e o próprio risco de esvaziamento de sentido dos direitos sociais como direitos constitucionais, vem provocando uma ruptura com a teoria clássica, no sentido de conferir, pelo menos em certa medida, aplicabilidade direta e imediata. Não tem sentido, pelo próprio significado histórico do Direito Constitucional, não atribuir um mínimo de eficácia imediata a um direito positivado na Constituição, se a Constituição surge justamente como um remédio ao arbítrio, submeter um direito positivado na Constituição ao voluntarismo político significa privá-lo do seu caráter de direito constitucional fundamental.

Em razão disso, leciona Canotilho:

Devido a essa ruptura à doutrina clássica, pode e deve-se dizer que hoje não há normas constitucionais programáticas. É claro que continuam a existir normas-fim, normas-tarefa, normas-programa que "impõem uma actividade" e "dirigem" materialmente a concretização constitucional. Mas o sentido destas normas não é o que Ihes assinalava tradicionalmente a doutrina: "simples programas, "exortações morais", "declarações", "sentenças políticas", "aforismos políticos", "promessas", "apelos ao legislador", "programas futuros", juridicamente desprovidos de qualquer vinculatividade. Às "normas programáticas" é reconhecido hoje valor jurídico constitucionalmente idêntico ao dos restantes preceitos da Constituição. Mais do que isso: eventual mediação da instância legiferante na concretização das normas programáticas não significa a dependência deste tipo de normas de interposição do legislador; é a positividade das normasfim e normas-tarefa (normas programáticas) que justifica a necessidade de intervenção dos órgãos legiferantes (CANOTILHO apud SAULE JÚNIOR, 1999, 93).

Ainda sobre as normas constitucionais programáticas na obra do mesmo doutrinador: 
Estas normas são todas diretivas materiais constitucionais e assumem relevo de uma tripla forma: (1) como imposições, vinculando o legislador, de forma permanente, à sua realização; (2) como directivas materiais, vinculando positivamente os órgãos concretizadores; (3) como limites negativos, justificando a possibilidade de censura em relação aos actos que a contrariam (CANOTILHO, 1994, 315).

Daí decorre a posição hoje mais aceita pela doutrina, de que o disposto contido no art. 5 , $\S 1^{0}$ se trata de uma norma de cunho inequivocamente principiológico, um princípio impositivo contendo um comando de maximização dos direitos fundamentais, estabelecendo o dever dos órgãos estatais de conceberem a maior eficácia possível aos direitos fundamentais.

\footnotetext{
Isso significa, em última análise, que, no concernente aos direitos fundamentais, a aplicabilidade imediata e eficácia plena assumem a condição de regra geral, ressalvadas exceções que, para serem legítimas, dependem de convincente justificação à luz do caso concreto, no âmbito de uma exegese calcada em cada norma de direito fundamental e sempre afinada com os postulados de uma interpretação tópico-sistemática. (SARLET, 2011, 271).
}

Assim, o Estado brasileiro tem obrigação de garantir minimamente o direito a moradia, de forma que ninguém possa ser privado de direito ou garantia sob o argumento de estar ele previsto em norma programática. $O$ fato das normas constitucionais programáticas não regularem imediatamente um objeto, mas preestabelecerem a si mesmo um programa de ação com respeito ao próprio objeto e se obrigando a não se afastar dele sem um motivo, infere que o direito à moradia impõe a poder público o dever de atuar positivamente em sua promoção e proteção enquanto meta constitucionalmente estabelecida, no sentido de proporcionar moradia digna a toda a população.

\section{O MEIO AMBIENTE COMO UM DIREITO FUNDAMENTAL.}

Tratada a questão do Direito Social à Moradia, passa-se a abordar da questão ambiental e da sua posição no ordenamento constitucional brasileiro. 
Os diversos problemas globais de ordem natural como a extinção de espécies animais e vegetais, as alterações climáticas, a redução vertiginosa das florestas e a poluição que nos trazem problemas práticos imediatos, aliado a busca da satisfação de novas necessidades da busca qualidade de vida, deixam claro que é necessária uma mudança de postura do homem frente à natureza. A cada ano milhares de dados levantados em pesquisas científicas tornam mais evidente que 0 desenvolvimento econômico das sociedades humanas, a qualidade de vida dessas comunidades e até mesmo a própria sobrevivência do ser humano como espécie estarão seriamente comprometidos sem uma gestão eficiente dos recursos naturais e sem medidas de saneamento do planeta.

O crescimento da consciência ecológica deve-se principalmente aos impactos ambientais provocados pelo ser humano sobre a terra que tem se refletido sobre a própria humanidade, e a compreensão de que as transformações provocadas ocorrem numa escala e velocidade muito maior do que o planeta é capaz de recuperar. Os efeitos da poluição industrial, o uso de combustíveis fósseis como matriz energética básica, o processo de desertificação que ameaça a capacidade de produzir alimentos, a destruição das florestas são fatos que deixam claro a limitação e a fragilidade dos recursos naturais, enquanto que por outro lado a população mundial vem crescendo exponencialmente. Basta se observar que a população mundial simplesmente duplicou nos últimos quarenta anos.

De fato, como é comumente apontado pelos estudiosos do Meio Ambiente, a crescente degradação ambiental é responsável pelo início da tutela estatal do meio ambiente, através do que JOSÉ AFONSO DA SILVA chama de despertar da "consciência ecológica" pela população, uma vez que chamou a atenção das autoridades para o problema da degradação e destruição do meio ambiente, natural e cultural, de forma sufocante $(2004,33)$. Da necessidade de proteção jurídica ao meio ambiente, com o combate a degradação ambiental e objetivando o equilíbrio ecológico, foram surgindo em todos os países as legislações ambientais. No entanto, essa legislação apresenta-se bastante variada, dispersa e confusa. Se por um lado têm-se normas ambiciosas, de base ecológica, que tentam relacionar os elementos envolvidos na situação para normatizar uniformemente as regras relativas ao meio ambiente, por outro é possível observar normas que constituem simples 
adequações da legislação sanitária e higienista do século XIX e também da que em outras épocas, protegiam a paisagem, a fauna e a flora.

No âmbito do Direito Constitucional, somente as constituições do pós-guerra passam a se referir ao meio ambiente. É assim com a Constituição da República Federal da Alemanha de 1949 ao tomar como prerrogativa da união disciplinar normas gerais sobre a caça, a proteção da natureza e a estética da paisagem (art. 75, 3ำ), e ao enunciar como prerrogativa concorrente da União e dos Estados o combate à poluição (art. 74, 4ํํ) (SILVA, 2004, 43).

Num sentido mais ambientalista temos as Constituições promulgadas no antigo bloco socialista na década de 70, como a búlgara de 1971, a cubana de 1976 e a soviética de 1977, sendo que as duas primeiras estabelecem como dever do Estado e da Sociedade a salvaguarda da natureza e dos recursos naturais e a última assegura a proteção da natureza no interesse das gerações presentes e futuras (SILVA, 2004, 45).

No entanto, é unanimidade que cabe ao ordenamento constitucional português o vanguardismo quanto ao tema, já que foi a Constituição da República Portuguesa de 1976 que deu a formulação contemporânea ao tema, correlacionando-o com o direito à vida, quando institui em seu art. 66 o direito de todos a um ambiente de vida humana sadio e ecologicamente equilibrado e o dever de todos de defender esse ambiente. Torna-se incumbência do Estado prevenir e controlar a degradação ambiental e a promoção de políticas públicas no sentido de proteger paisagens e sítios, conservar a Natureza, e preservar valores culturais de interesse histórico ou artístico. Também trata como dever do Estado promover o aproveitamento racional dos recursos naturais, salvaguardando a sua capacidade de renovação e a estabilidade ecológica(SILVA, 2004, 45).

No plano normativo internacional, é importante lembrar a Conferência das Nações Unidas de 1972 em Estocolmo, que institui a Convenção relativa à proteção do Patrimônio Mundial, Cultural e Natural, que reconhece o interesse excepcional sobre o patrimônio ambiental e cultural e o caráter incomparável e insubstituível desses bens (COMPARATO, 2003, 382), bem como reconhece como direito fundamental do homem à qualidade do meio ambiente. 
O homem tem o direito fundamental à liberdade, à igualdade e ao desfrute de condições de vida adequada em meio cuja qualidade the permite levar uma vida digna e gozar de bem estar e tem a obrigação de proteger e melhorar esse meio para as gerações presentes e futuras. (SILVA, 2004, 59).

No âmbito constitucional brasileiro, a Constituição de 1988 foi a primeira a tratar claramente da questão ambiental. O núcleo normativo do Direito Ambiental na Constituição encontra-se no art. 225 de cujo caput é possível se extrair o status da questão ambiental no texto constitucional:

Art. 225. Todos têm direito ao meio ambiente ecologicamente equilibrado, bem de uso comum do povo e essencial à sadia qualidade de vida, impondo-se ao Poder Público e à coletividade o dever de defendê-lo e preservá-lo para as presentes e futuras gerações.

De fato, o Direito ao Ambiente sadio e ecologicamente equilibrado é há muito considerado pela doutrina e pela jurisprudência com uma extensão do direito à vida. Assim, quando se fala em tutela do meio ambiente, tem-se em jogo formas de garantir a qualidade de vida humana, pois the é essencial. $O$ equilíbrio ecológico nessa relação tão direta com o ser humano faz do direito ao ambiente um direito fundamental da pessoa humana, em função dos elementos e valores que congrega, como saúde, segurança, cultura, identidade. Preservar o patrimônio ambiental é garantir vida sadia e com qualidade. Garantir vida com qualidade é promover a dignidade da pessoa humana.

O estado de degradação ambiental chega a um ponto tal que, não apenas a qualidade de vida que preocupa, mas a própria existência de vida. São muitos os estudos que apontam que, em se mantendo o atual ritmo de degradação ambiental, como o aquecimento global, extinção em massa de espécies de seres vivos, é possível que o planeta no futuro não seja mais capaz de suportar a vida humana.

Sob esse ponto de vista, não restam dúvidas de que o direito ao ambiente sadio é também um direito fundamental de todos no ordenamento jurídico brasileiro. Se não se encontra previsto expressamente no Título II da Constituição, onde estão enumerados formalmente alguns direitos fundamentais, o direito ao meio ambiente equilibrado, por este abranger elementos essenciais à vida, há que ser considerado direito fundamental, por ser mesmo uma nova forma de proteção ao direito à vida. $\mathrm{A}$ 
tutela do meio ambiente, dessa forma, se faz assim imperiosa porque proteger a qualidade de meio ambiente é proteger as condições essenciais para a própria existência de vida.

Além disso, considerando-se que a Constituição Federal de 1988 insere a defesa do meio ambiente como princípio da ordem econômica, significa que toda a atividade produção econômica do país está condicionada ao respeito ao meio ambiente.

\footnotetext{
Art. 170. - A ordem econômica, fundada na valorização do trabalho humano e na livre iniciativa, tem por fim assegurar a todos existência digna, conforme os ditames da justiça social, observados os seguintes princípios:

(....)

$\mathrm{VI}$ - Defesa do meio ambiente, inclusive mediante tratamento diferenciado conforme o impacto ambiental dos produtos e serviços e de seus processos de elaboração e prestação.
}

Pelo texto constitucional, a ordem econômica não tem outro fim que não assegurar a todos uma existência digna conforme os ditames da justiça social. Não é possível se falar em justiça social sem se garantir a todas as pessoas meios materiais para que possa viver com qualidade de vida, conforto conforme suas necessidades físicas e psíquicas.

Ora, não é outro o fim da tutela do meio ambiente senão tomar medidas no sentido de garantir, sob o ponto de vista de recursos naturais, a existência desses meios. Se a tutela do direito ambiental em si não garante justiça social - e nem é seu fim garantir -, por outro lado, seria impossível concreção de justiça social sem a preservação dos recursos naturais e dos diversos fenômenos biológicos do planeta. A função do direito ambiental é justamente garantir a preservação e a continuidade desses recursos para que sejam de acesso universal, das presentes e futuras gerações.

Inegável portanto, a importância conferida pela Constituição da República a questão ambiental e o status constitucional conferido a tutela do meio ambiente, além da própria compreensão de que o direito ambiental - as normas jurídicas de proteção ao meio ambiente equilibrado - não tem outra razão de ser que não o direito ao ambiente, assim compreendido como o direito fundamental de cada pessoa a um ambiente sadio e que Ihe proporcione qualidade de vida. 


\section{COLISÃO DE NORMAS CONSTITUCIONAIS: DIREITO FUNDAMENTAL À MORADIAS E DIREITO AO MEIO AMBIENTE EQUILIBRADO.}

Como visto, tanto o direito ao meio ambiente, como um direito fundamental de toda a coletividade humana, quanto o direito à moradia, como um direito fundamental social estão tutelados pela Constituição de 1988.

Como então resolver a situação da ocupação de áreas de proteção ambiental, que trazem contínuos prejuízos ao meio ambiente, como por exemplo uma possível poluição de mananciais ou mesmo supressão de áreas verdes, sem por outro lado, retirar de um número razoável de pessoas a única forma que encontraram de acesso a moradia? Desnecessário relembrar que a ocupação dessas áreas se dá especialmente em razão da falta de um planejamento adequado do Estado, acompanhado de políticas sociais que garantissem efetivamente a função social das cidades, e que até então conivente ou no mínimo negligente diante dessa situação. BARROSO trata com naturalidade a colisão de normas constitucionais, por entender as Constituições como documentos dialéticos e compromissórios, que consagram valores e interesses diversos, e que por isso, eventualmente entram em rota de colisão (2012, 423).

A solução nesses casos pode ser obtida por via legislativa, ou a solução dos conflitos por via de legislação ordinária sempre que for possível se identificar ou se prever as situações de tensão ou de colisão de direitos fundamentais no caso concreto, a vista da experiência, ou então por via judicial, quando a solução não for legislada, ou quando - não raro - a solução idealizada pelo legislador é insuficiente ou inadequada à solução do caso em discussão, em razão das próprias peculiaridades deste.

A edição da medida provisória de ㄲo. 2.220 de 4 de setembro de 2001, que trata da concessão especial de uso de sem dúvidas, é um exemplo da busca de solução, buscando equacionar a questão do direito à moradia com a inalienabilidade dos bens públicos.

$\mathrm{Na}$ resolução desses casos pela via judicial, não é possível que o julgador simplesmente opte por uma das normas, direitos ou interesses constitucionalmente 
protegidos em detrimento dos demais. Vige entre nós o princípio da unidade da Constituição segundo o qual a constituição é um todo, uma estrutura sistemática, um conjunto de normas onde uma norma não pode ser analisada isoladamente, mas no contexto das demais normas integrantes do sistema no qual está inserida, daí decorrendo uma interdependência dessas normas. Daí não ser reconhecido em nosso direito constitucional a possibilidade de hierarquia entre as normas constantes da constituição e por isso não é possível uma escolha arbitrária da norma ou direito que prevalecerá.

Assim, se faz necessária a construção argumentativa, à luz dos elementos do caso concreto, através do uso da ponderação e do princípio da proporcionalidade, qual a solução mas adequada à vontade da Constituição - considerada em seu conjunto -, no conflito específico a ser resolvido.

Diferente das situações típicas em que um caso discutido sob a análise jurídica tem suas repercussões jurídicas facilmente encontradas, por meio da simples subsunção do fato concreto à norma jurídica, é necessária o desenvolvimento de uma solução criativa do interprete.

\begin{abstract}
Como se registrou, são situações em que a solução não estará pronta em uma prateleira jurídica, e, portanto, exigirá uma atuação criativa do interprete, que deverá argumentativamente, justificar seu itinerário lógico e suas escolhas. Se a solução não está integralmente na norma, o juiz terá de recorrer a elementos externos ao direito posto, em busca do justo, do bem, do legítimo. Ou seja, sua atuação terá de se valer da filosofia moral e da filosofia política (BARROSO, 2012, 424).
\end{abstract}

De toda forma, cumpre-se observar que, tratando-se da solução de conflitos entre normas constitucionais ou direitos fundamentais, por tudo o que foi exposto o interprete da norma haverá necessariamente que escolher pela limitação de um dos direitos envolvidos em benefício do outro.

Essa escolha, tendo como pressuposto o princípio da unidade da constituição, deverá respeitar alguns princípios instrumentais, buscando a equação das entre as normas em conflito, que, em apertada síntese, podem ser resumidos:

a) Princípio da necessidade - segundo o qual a regra de solução somente terá legitimidade quando for real o conflito, ou, quando seja realmente necessária a ponderação, por impossibilidade efetiva de se REVISTA DO DIREITO UNISC, SANTA CRUZ DO SUL No $41 \mid$ p. 65 - 88| NOV - DEZ 2013 
estabelecer a convivência entre os direitos conflitantes. (ZAVASCKY, 1995, 18)

b) Princípio da Concordância Prática - que exige do interprete a busca de uma solução harmoniosa para o conflito, que permita a coexistência das normas e direitos constitucionais em choque, evitando o sacrifício total de um dos direitos conflitantes, ou que se perca seu núcleo essencial. Decorre ainda desse princípio que a atuação do interprete não deve ir além do mínimo necessário para a harmonização pretendida, respeitando, nesse sentido evocando o princípio da proporcionalidade, guardando a adequação entre os fins e os meios.

Embora a jurisprudência ainda não revele uma direção clara do posicionamento dos tribunais, parece ser a tendência atual a busca da harmonização ou concordância prática no caso concreto, das normas ou direitos colidentes. Para ilustrar as possibilidades de atuação dos tribunais nessas situações, apresenta-se texto de julgado recente do Tribunal de Justiça do Estado de São Paulo apontando para a harmonização do conflito entre a Direito à Moradia e Direito ao Ambiente.

A doutrina constitucionalista elenca, dentre os princípios de interpretação constitucional, o da concordância prática ou harmonização, decorrente dos princípios da força normativa e da unidade da Constituição, além da máxima efetividade ou maior efetividade possível das normas constitucionais.

Segundo o princípio da concordância prática, quando ocorrerem conflitos entre normas constitucionais ou direitos fundamentais, deve-se evitar o sacrifício total de um deles e adotar a solução que promova, na maior medida possível, a eficácia de ambos.

Diante da incidência de tal princípio no caso concreto dos autos, seria inadequado sacrificar totalmente o direito à moradia, como fez a r. sentença recorrida, ainda mais quando se tem em conta que a ocupação existe há muitos anos e o Estado, ao invés de debelá-la de pronto, não somente se omitiu, como ainda efetuou prestações positivas, fornecendo aos moradores do local os principais serviços de infraestrutura.

Por outro lado, é igualmente inadequado sacrificar o direito ao meio ambiente equilibrado com a declaração de total improcedência da ação e a permanência impune do apelante no terreno, como decidido no acórdão mencionado. 
Reformando a sentença de primeiro grau para excluir a demolição da moradia no município de Ubatuba, mas mantendo a demolição das demais construçõesexistentes na área também edificadas pelo réu, bem como, determinando ao apelante se abster-se de novos danos e recompor a vegetação.

\begin{abstract}
Ao contrário, penso ser possível realizar a mencionada harmonização, excluindo-se da sentença apenas a ordem de demolição da casa onde reside o apelante, mantida a demolição das demais edificações, com a qual o próprio apelante, em manifestação ofertada no bojo do inquérito civil que deu origem à ação, demonstrou concordância.

Com isso, o apelante tem resguardado seu direito à moradia, mas, ao mesmo tempo, permanece obrigado a se abster de causar novos danos ambientais e recompor a vegetação.

A forma com que se dará o cumprimento de tais obrigações deve ser estabelecida pelos órgãosambientais competentes levando em consideração a necessidade de respeitar o direito à moradia, de forma que o reflorestamento não impeça, por exemplo, o acesso da residência à via pública.
\end{abstract}

Verifica-se assim, a preocupação do poder judiciário no julgado em análise em manter o núcleo essencial de cada direito fundamental, buscando manter o direito à moradia, ao rechaçar a demolição da construção que serve a esse propósito efetivamente, mas não concedendo 0 mesmo efeito às demais construções edificadas pelo réu e que guarneciam sua moradia, sendo que neste caso, além das demolições, o acordão determina ainda a proibição de novas edificações e o reflorestamento. O reflorestamento, no caso, a ser realizado na forma determinada pelos órgãos deliberativos, consultivos e fiscalizatórios de competência para exercício de poder de polícia na área ambiental, visto que a questão trata de competência concorrente entre Estado, Município e União. Interessante notar ainda a ressalva do órgão judiciário para que os órgãos ambientais em suas ações respeitem o direito à moradia, buscando a concordância prática no caso concreto, como por exemplo quando determinam que as ações de reflorestamento não interfiram por exemplo no acesso da residência do réu à via pública, garantindo o direito de passagem. Segue a ementa do julgado:

EMENTA: Apelação - Ambiental - Ocupação irregular de APP - Sentença que condena o apelante a se abster de atividades danosas e reparar 0 
dano, inclusive com a demolição de residência existente no local - Matéria fática incontroversa - Questão que se resolve, no entanto, parcialmente em prol do apelante - Diante do conflito entre os direitos fundamentais ao meio ambiente e à moradia, deve-se adotar a solução que promova a maior eficácia possível de ambos - Aplicação do princípio da concordância prática ou harmonização - Sentença parcialmente reformada, para excluir a ordem de demolição da residência, mantidas as demais providências de conservação e reparação ambiental - Apelo parcialmente provido.

BRASIL. Tribunal de Justiça do Estado de São Paulo. Matéria Ambiental. Apelação No. 0004414-75.2011.8.26.0642. Relator Desembargador Souza Nery. São Paulo, SP, 24 de Outubro de 2013.

Portanto, em sede de Ação Judicial, tem conseguido o poder judiciário harmonizar a questão do direito à moradia com a questão da preservação ambiental como requisito para o direito ao ambiente. Ressalte-se, é claro, que a solução em tais casos não segue uma forma pronta e acabada. Como é da própria natureza desses casos, a solução pela harmonização de direitos fundamentais em conflito surgirá da análise do caso em concreto, o que só permitirá análises mais profundas com o surgimento de novos julgados que versem sobre 0 conflito do direito fundamental à moradia com o direito ao meio ambiente ecologicamente equilibrado.

\section{CONSIDERAÇÕES FINAIS}

Após a análise dos direitos fundamentais à moradia e ao meio ambiente, verificada a razão de sua incorporação ao texto constitucional por sua fundamentalidade e uma vez verificado o tratamento constitucional dado a ambos os direitos, verifica-se que a melhor solução para o caso de conflitos entre direitos de tamanha importância deve necessariamente passar pela ponderação de interesses e valores, de modo a se preservar o núcleo essencial de ambos os direitos constitucionalmente protegidos.

Se por um lado à moradia como direito fundamental é uma conquista paulatina advinda do surgimento do Estado Social, e construída através d e um processo histórico em que se amplia a noção de direitos fundamentais para além das liberdades públicas do estado liberal para atingir o atendimento de necessidades matérias do ser humano, por outro lado o direito ao ambiente surge da compreensão de que a própria vida humana, o primeiro direito fundamental a ser reconhecido, está 
interligada aos demais fenômenos biológicos do planeta e deles depende para a sua continuidade. Do ponto de vista da dignidade humana como princípio fundamental da República, ambos os direitos são de igual importância e dirigem-se para aquele mesmo fim.

Se por um lado acelera-se a degradação ambiental do planeta, pelo uso inadequado dos recursos naturais e pela poluição, por outro lado, o fenômeno urbano e a desigualdade social pressionam a população de baixa renda para as áreas marginais das cidades, onde estas pessoas sem grandes alternativas procurarão modos de se estabelecer e morar.

Ver a ocupação de certas áreas de especial interesse ambiental como ato de vilania, significa deixar de enfrentar a fundo o verdadeiro problema, já que a população de baixa renda que recorre a ocupação de áreas de preservação o fazem por falta de opção, e normalmente com a omissão ou conivência do poder público, já que a alternativa - propiciar a todos lugar e condições dignas de morar - é muito mais onerosa.

Percebe-se que a colisão dos direitos constitucionais analisados tem como principal raiz a ineficiência do Estado, tanto em promover políticas públicas adequadas de fomento a moradia, como de controlar e proteger adequadamente as áreas de proteção ambiental, levando o judiciário, quando da colisão dos direitos a intervir para solucionar o problema no caso concreto.

Considerando-se isso, e somada a fundamentalidade dos direitos constitucionalmente protegidos em questão, qualquer solução jurídica para o conflito de direitos, ou para o conflito de interesses balizados nesses direitos passará necessariamente pela ponderação de valores, de forma a resolver o problema preservando-se o núcleo essencial de cada direito em questão, posto que como direito fundamentais emanam deles escolhas políticas do povo, enquanto sociedade politicamente organizada. É importante salientar que não havendo soluções prontas para esse tipo de problema, conforme a própria doutrina aponta, buscar-se-á a ponderação, visando a concordância prática dos direitos em conflito no caso concreto, de forma a não se permitir o sacrifício de nenhum dos direitos no caso concreto, sem o quê não faria sentido chama-los de fundamentais, e acima de tudo, como postulado básico buscando manter a harmonia e unidade da constituição. 


\section{REFERÊNCIAS.}

BARROSO, Luis Roberto. Curso de direito constitucional contemporâneo: os conceitos fundamentais e a construção do novo modelo. 3. ed. São Paulo: Saraiva. 2012.

BERÉ, Cláudia Maria. Legislação urbanística: a norma e o fato nas áreas de proteção aos mananciais da região metropolitana de São Paulo. São Paulo SP: Faculdade de Arquitetura e Urbanismo - USP, 2005 (Dissertação de Mestrado em Arquitetura e Urbanismo).

BRASIL. Constituição da República Federativa do Brasil. Promulgada em 5 de outubro de $1988 . \quad$ Disponível em www.planalto.gov.br/ccivil_03/constituicao/constituicao.htm. Acesso em: 27/10/2013.

BRASIL. Tribunal de Justiça do Estado de São Paulo. Matéria Ambiental. Apelação No. 0004414-75.2011.8.26.0642. Relator Desembargador Souza Nery. São Paulo, SP, 24 de Outubro de 2013.

BRASIL. Medida provisória de No. 2.220 de 4 de setembro de 2001.Dispõe sobre a concessão de uso especial de que trata o $\S 10$ do art. 183 da Constituição, cria o Conselho Nacional de Desenvolvimento Urbano - CNDU e dá outras providências. Disponível em: http://www.planalto.gov.br/ccivil_03/mpv/2220.htm. Acesso em 28/10/2013.

BRITO, F.; HORTA, C. J. G.; AMARAL, E. F. deL. A Urbanização Recente no Brasil e asAglomerações Metropolitanas. In: ABEP - GTMIGRAÇÃO. Associação Brasileira de EstudosPopulacionais. $\quad$ Anais... $2001 . \quad$ Disponível em:<http://www.abep.nepo.unicamp.br/iussp2001/cd/GT_Migr_Brito_Horta_Amaral_ Text.pdf>. Acessoem: 23dezembro. 2013. 
CANOTILHO, José Joaquim Gomes. Constituição Dirigente e Vinculação do Legislador. Coimbra: Coimbra Editora, 1994,

COMPARATO, Fábio Konder. A afirmação histórica dos direitos humanos. 3. Ed., São Paulo: Saraiva, 2004.

COULANGES, Fustel de. A cidade antiga. Trad. Jonas Camargo Leitee Eduardo Fonseca. São Paulo: Hemus, 1975.

ESTADOS UNIDOS MEXICANOS. Constitución politica de los Estados Unidos Mexicanos. Disponível em:www.diputados.gob.mx/LeyesBiblio/pdf/1.pdf. Acesso em 27/10/2013.

GERMANI, Guiomar Inez. Condições históricas e sociais que regulam o acesso a terra no espaço agrário brasileiro. GeoTextos, Vol. 2, N. 2, 2006.

IMPÉRIO ALEMÃO. Constitución del Império Alemán de 11 de agosto de 1919. Disponível: http://portu.der.uva.es/constitucional/verdugo/Constitucion_Weimar.pdf. Acesso em: 27/10/2013.

MELO, Lígia. Direito à moradia no Brasil. Política urbana e acesso por meio da regularização fundiária. Belo Horizonte: Fórum, 2010.

ORGANIZAÇÃO DAS NAÇÕES UNIDAS. Declaração universal dos direitos do homem.

Disponível em: portal.mj.gov.br/sedh/ct/legis_intern/ddh_bib_inter_universal.htm. Acesso em 27/10/2013.

Pacto Internacional dos Direitos Econômicos, Sociais e Culturais.

Disponível em: http://www.oas.org/dil/port/1966\%20Pacto\%20Internacional\%20sobre\%20os\%20Dire 
itos\%20Econ\%C3\%B3micos,\%20Sociais\%20e\%20Culturais.pdf. Acesso em 27/10/2013.

. The Vancouver declaration on humans settlements. Disponível em: http://www.unhabitat.org/downloads/docs/924_21239_The_Vancouver_Declaration.p df. Acesso em 27/10/2013.

SARLET. Ingo Wolfgang Sarlet. A eficácia dos direitos fundamentais. Uma teoria geral dos direitos fundamentais na perspectiva constitucional. 10. Ed., Porto Alegre: Livraria do Advogado, 2011.

SAULE JÚNIOR. O direito à moradia como responsabilidade do estado brasileiro. Direito à cidade. Trilhas legais para o direito às cidades sustentáveis. São Paulo: Max Limonad, 1999.

SILVA, José Afonso da.Direito Ambiental Constitucional. 5. ed., São Paulo: Malheiros, 2004.

. Curso de direito constitucional positivo. 24. Ed., São Paulo: Malheiros, 2005.

ZAVASCKI, Teori Albino. Antecipação da tutela e colisão de direitos fundamentais. Revista do Tribunal Regional Federal:1 Região, V. 7, N. 3, p. 15- 32, jul./set. 1995. 